\title{
Management Strategies for Ethics in International Research
}

\author{
Emmanuelle Lévesque $\cdot$ Bartha Maria Knoppers
}

Published online: 19 September 2014

(C) Springer Science + Business Media New York 2014

\begin{abstract}
PERSPECTIVE is a large-scale, international research project that aims to develop a risk stratification approach for breast cancer screening. This project involving many researchers as well as samples and data from 30 different countries creates novel ethical challenges. We discuss some specific issues that have arisen in the context of the PERSPECTIVE project as well as the innovative strategies conceived to address them. Even in the absence of an overarching international organization for the ethics review of multisite research projects, an adapted, flexible ethical framework, together with customized sample and data sharing tools, and a multi-step process for ethics approvals were successful strategies.
\end{abstract}

Keywords Ethics - Sample and data sharing - Breast cancer $\cdot$ Confidentiality $\cdot$ Ethical framework

\section{Introduction}

In 2013, we launched a large-scale international research project on breast cancer screening, entitled PERSPECTIVE [1]. This project raised a plethora of ethical questions: sample and data sharing; impact on insurability; jurisdiction issues; retrospective use of samples; data banking for future research; and the communication of incidental findings from exome sequencing. Many

\section{E. Lévesque $(\varangle) \cdot$ B. M. Knoppers}

Department of Human Genetics, Faculty of Medicine, Centre

of Genomics and Policy (CGP), McGill University, 740,

Dr. Penfield Avenue, Montreal, QC H3A 1A4, Canada

e-mail: emmanuelle.levesque@mcgill.ca

B. M. Knoppers

e-mail: bartha.knoppers@mcgill.ca researchers have commented on the incredible amount of time and resources devoted to such ethical challenges [25]. Indeed, delays and costs associated with ethics review processes are often considered to be an "unethical barrier" to potentially beneficial research of minimal risk that could improve care [6].

Charged with the ethics management and the related approvals of the PERSPECTIVE project, we soon reached the conclusion that it would be necessary to develop a strong and inventive work plan to avoid being caught in this web of barriers. While institutions and countries are still not responding to the call by researchers for a critical reexamination and "revamping" of the ethics review process affecting international projects, we devised some strategies to manage the current process.

We focus on 3 elements for the efficient management of the challenges raised by PERSPECTIVE: (1) an adapted, flexible ethical framework, (2) customized sample and data sharing tools, and (3) a multi-step process for ethical approvals. It is our hope that our approach will be helpful for other international consortia. Although built for an international project on breast cancer, the management strategies presented below could be translated and used in many other international cancer projects or in international research in general.

\section{An International Research Project on Cancer Involving 30 Countries}

The 4-year PERSPECTIVE research project aims to develop a risk stratification approach for breast cancer screening. This approach consists of classifying each woman, through a genetic screening test and personal risk factors, onto a risk level (e.g., near population risk; 
intermediate risk; or high risk). This classification could allow the earlier identification of younger women (approximately 35 to 49 years old) currently excluded from population screening programs who are at intermediate or high risk. Stratification would give timely access to adapted screening measures to this sub-group of women under 50 years of age. Screening (i.e., mammogram or ultrasound) could then be offered earlier and/or more frequently to such women. Although this approach seemed to be revolutionary during the building phase of the project in 2012, researchers are beginning to advocate for the implementation of such risk-based screening strategies for breast cancer [7-9].

PERSPECTIVE is building 4 tools under this approach:

- A clinical genetic screening test (to detect common and low frequency genetic variants);

- An individual risk prediction model incorporating genetic and non-genetic risk factors (to allow health professionals to classify women);

- An online population risk stratification simulation model (to enable decision-makers to determine the most appropriate and cost-beneficial screening scenarios); and

- Risk communication tools (to help women and health professionals to understand risk stratification).

Standard biological analysis (e.g., sequencing) coexists with this tool-building exercise as well as social science research that includes interviews and questionnaires.

The parts of the project that raise the most ethical challenges are the development of a genetic screening test and the improvement of an individual risk prediction model. Together, these parts involve the analysis of more than 90,000 samples and data from 65 studies located in 30 countries. Building the population risk prediction model also requires obtaining data from approximately 12,000 individuals from hospital and governmental databases. Complexity is further increased due to the fact that sample and data analyses take place in 4 different laboratories located in 3 countries. At the end of each stage of the project, the majority of data collected and analyzed will be stored in a central database at Cambridge University (UK). This central database is intended to be used for future (unspecified) research.

The project also collaborates with an existing research platform, the Breast Cancer Association Consortium (BCAC). This Consortium brings together 89 groups involved in current or past breast cancer research. Significant number of samples and data will be provided by the groups involved in this Consortium and the results from their analysis by PERSPECTIVE will also be stored in the central database in Cambridge.

\section{An Adapted, Flexible Ethical Framework}

Working with many jurisdictions on sensitive topics presupposes a multiplicity of non-harmonized positions on ethics from multiple jurisdictions. For example, some of our partners in the UK do not need ethics approvals for epidemiological analyses on phenotypic data lacking direct identifiers. In contrast, Canadian researchers must obtain ethics approvals for such analyses. Contradictory positions also abound concerning the return of individual results to participants who have provided samples. While some European partners do not have an ethical obligation to return incidental findings unrelated to breast cancer, Canadian researchers could be obliged to return any unanticipated discoveries having significant "welfare" implications for the participant [10]. In fact, inconsistency emerges not only from the geographical and jurisdictional origins of the data and samples, but also in temporal aspects. In fact, discrepancy is exacerbated by the use of previously collected data and samples (sometimes a decade ago), resulting in a "forced" marriage between former and contemporary ethical rules. Thus, alternative and flexible solutions allowing the integration of a wide range of ethical positions should be considered.

Our framework addresses this diversity of rules and policies and enhances the flexibility of the modalities for the implementation of ethical principles.

Indeed, a distinction remains between "principles" and "modalities". The core ethical principles are likely the same (e.g., protection of persons, maximization of benefits, non-maleficence), but the modalities to implement these principles may-and in fact do-vary widely. Thus, we strive to keep an open mind in order to navigate through opposing modalities resulting from interpretation and use of the same core principles.

Table 1 summarizes some issues encountered, their variability, and the strategies used. This strategy required the cohabitation of different and contradictory modalities, as well as the creation of processes to ensure that local requirements are duly respected. Obviously, this creates an unanticipated level of complexity for the management of data and samples. Each set of samples and data has some restriction that prevents or limits use. Restrictions depend on the types of analyses; diseases; jurisdiction, and limits (if any) to sample/data sharing. For example, while PERSPECTIVE uses mostly coded samples, a few anonymized samples will be used to respect the original consent. By their very nature, anonymized results can never be linked to the phenotype data of a person. However, there is still some research potential with these anonymized samples. 
Table 1 Ethical issues and flexibility

\begin{tabular}{|c|c|c|}
\hline Issue & Variability range & Flexibility used \\
\hline $\begin{array}{l}\text { Requirement of } \\
\text { ethics approval }\end{array}$ & $\begin{array}{l}\text { Not required for } \\
\text { epidemiologic data } \\
\text { analysis; required } \\
\text { for non anonymized } \\
\text { data analysis; not } \\
\text { required for sample } \\
\text { analysis with } \\
\text { contracting out } \\
\text { service using coded } \\
\text { samples where no } \\
\text { access to the code; } \\
\text { required for any } \\
\text { sample analysis... }\end{array}$ & $\begin{array}{l}\text { Approval required } \\
\text { according to local } \\
\text { law, policies and } \\
\text { guidelines }\end{array}$ \\
\hline $\begin{array}{l}\text { Confidentiality } \\
\text { protection method } \\
\text { (data \& samples) }\end{array}$ & $\begin{array}{l}\text { Coding with linkage } \\
\text { to a central } \\
\text { database; mandatory } \\
\text { anonymization; } \\
\text { method not } \\
\text { specified }\end{array}$ & $\begin{array}{l}\text { Coding with linkage } \\
\text { to the central } \\
\text { database, unless } \\
\text { prohibited by local } \\
\text { provider or lack of } \\
\text { consent }\end{array}$ \\
\hline Incidental findings & $\begin{array}{l}\text { Obligation to return } \\
\text { specific results; no } \\
\text { guidelines on return; } \\
\text { return not allowed }\end{array}$ & $\begin{array}{l}\text { Managed as required } \\
\text { by the rules of the } \\
\text { provider's } \\
\text { jurisdiction or } \\
\text { governed by former } \\
\text { consent where } \\
\text { specified }\end{array}$ \\
\hline $\begin{array}{l}\text { Access to data for } \\
\text { future research } \\
\text { (from the central } \\
\text { database) }\end{array}$ & $\begin{array}{l}\text { Wide access for } \\
\text { research; limited to } \\
\text { a few research } \\
\text { domains; not } \\
\text { mentioned }\end{array}$ & $\begin{array}{l}\text { Opt-out option for the } \\
\text { data provider (when } \\
\text { proposed use is not } \\
\text { permitted by local } \\
\text { rules or not } \\
\text { permitted or not } \\
\text { specified in consent) }\end{array}$ \\
\hline
\end{tabular}

\section{Alternative Arrangements for Ethics Approval}

Ethical aspects of large-scale international research projects involving complex sample and data transfers are hard to manage. The inherent difficulties encountered are not only experienced by researchers, these projects but also pose quite a challenge for ethics committees. The rules, procedures, and structures of ethics committees-as with other organizations - are usually not adaptable for exceptional situations. Acknowledgement of this situation, both by researchers and ethics committees, could be a first step toward the adaptation of the ethics review.

In Canada, the ethics policy applicable to almost all research conducted in universities and hospitals allows for the establishment of alternative ethics review models or arrangements appropriate for the research under review [9]. Thus, we initiated some different arrangements.

One of these arrangements involved dividing the process into several stages to avoid congestion of the complex issues that do not necessarily require simultaneous resolution. When possible, a large project may be split into a few smaller parts that can be run almost "separately" to allow the evaluation and approval of each part in sequence. Such a multi-step ethics approval may also manage ethics issues that cannot be defined or foreseen at the beginning of the project. In large-scale projects spanning over several years, there are many ethical issues known at the beginning, but others arise as the project progresses. Ongoing project development-particularly unavoidable changes on practical issues (e.g., the origin of the samples and data; the exact type of analysis to be done; and local restrictions on sample and data providers)—often makes it impossible to identify all ethical issues from the beginning.

Hence, we invited our principal ethics committee to adapt its review process into 7 stages by regrouping similar types of analyses together. Activities related to biological analyses were separated from activities related to social sciences, creating 1 principal study with 6 sub-studies. The sub-study related to social sciences was further split into 3 sub-studies due to their very different nature and in order to avoid unnecessary delaying of other activities.

The second arrangement concerned the recognition of the ethics approvals obtained from the numerous providers of samples and data. Samples and data come from many countries with distinct ethical frameworks. The ethics committee in charge of approving foreign samples analyses must take reasonable precautions to ensure that local ethics policies are duly respected. While a specific ethics committee cannot know and apply ethical concepts and laws from around the world, it can nevertheless rely on some kind of proof or records indicating that the applicable obligations have been fulfilled. To facilitate this task, we used 3 strategies:

- Creation of a table of ethics approvals status for the whole international project (continuously updated and shared with the Canadian ethics committees);

- Confirmation with transfer agreements that appropriate ethics approvals (or legal authorization) and informed consent were obtained; and

- Receipt of confirmation letters from sample and data providers concerning their own ethical status and related obligations.

The confirmation letter provides information on key elements related to potential core ethical concerns: (1) measures to protect confidentiality, (2) plans for managing individual results, (3) ethics approval status, and (4) the existence of a sample/data management policy and transfer agreement. With this on record, ethics committees are informed about essential elements of already collected samples and data in another jurisdiction (which are likely managed with distinct ethical rules), and thus may make an informed decision about their use. 
Indeed, appropriate adaptations for ethics reviews may improve and enhance the process. However, since the onus of initiating and developing these adaptations is on the local research teams and institutions-and their ethics committees-some authors may deem it unrealistic to expect them to dedicate the necessary energy to make the necessary adaptations [11].

\section{Integrated and Customized Sample and Data Sharing Tools}

As previously explained, 90,000 samples and associated data will make a trip from their countries of origin ( 65 studies in 30 countries) to 4 laboratories in 3 countries. Some of them will also make a round trip from a sequencing laboratory to a bioinformatics laboratory. In the end, results will be stored in a central database for future unknown projects. Most of the samples and data which will be used for PERSPECTIVE will be provided by BCAC members, already governed by sharing rules and regulations.

We conceived two integrated and customized tools for this sample and data sharing.

Sharing can occur in both, when required for analysis in the project and when used for future, unspecified research projects. Thus, both possibilities were integrated into customized transfer tools. Uniform rules for the management of sharing were made clear from the outset by integrating existing BCAC consortium data sharing rules. Samples and data obtained under different conditions at different times may be shared using these tools.

Moreover, with our collaboration, customized tools were developed by our colleagues in the UK (where the BCAC consortium and central database are located). Table 2 details the tools and some of their characteristics. First, a Memorandum of Understanding established the broad terms according to which samples and data would be managed and transferred between collaborators, and then two other agreements (one for data only and another for both samples and data) were drawn up for the application of these principles for when a transfer occurs. The transfer agreement for both samples and data may be adjusted for each transfer. In fact, while data transfer agreements can proceed very quickly, material transfer agreements for samples are more problematic. They often need to be adjusted, since the laws and regulations regarding the exchange of biological samples differ considerably across jurisdictions.

Certain aspects merit particular attention in the context of developing customized tools for sharing: (A) the sharing of results and confidentiality protection and (B) the involvement of incentives to share results.
Table 2 Developed samples and data sharing tools

\begin{tabular}{|c|c|c|}
\hline Tool & Scope & Aim \\
\hline $\begin{array}{l}\text { Memorandum of } \\
\text { understanding }\end{array}$ & $\begin{array}{l}\text { Samples and } \\
\text { data }\end{array}$ & $\begin{array}{l}\text { Current and future } \\
\text { projects }\end{array}$ \\
\hline Data transfer agreement & Data & $\begin{array}{l}\text { Current and future } \\
\text { projects }\end{array}$ \\
\hline $\begin{array}{l}\text { Material transfer } \\
\text { agreement }\end{array}$ & $\begin{array}{l}\text { Samples and } \\
\text { data }\end{array}$ & $\begin{array}{l}\text { Limited to the current } \\
\text { project }\end{array}$ \\
\hline
\end{tabular}

(A) The Sharing of Results and Confidentiality Protection

Sharing research results maximizes research potential and provides fair returns to the public for their participation and investment in research. Sharing results is not an option, but an obligation. Sharing results is primarily an ethical obligation, but it is often an administrative obligation imposed by funding agencies. The PERSPECTIVE funding agency policy on data sharing commits the agency to "the principle of rapid data release and sharing of unique resources to the scientific community" [12]. It implies that a reasonable effort should be made to have the data available "in a timely fashion with minimal or no restrictions" [11].

Often funding agencies also require the research teams to develop and to apply a data sharing plan. The PERSPECTIVE sharing plan is based on the principle of Open Science, which urges researchers to promptly release data and results. Indeed, the funding policy governing PERSPECTIVE stresses the importance of ensuring protection of participant privacy and confidentiality. A balance must be struck between broad data sharing and the protection of the privacy and confidentiality of participants. It complies with the Organisation for Economic Co-operation and Development (OECD) Principles and Guidelines for Access to Research Data from Public Funding [13]. Not only do these Principles and Guidelines promote a culture of openness and sharing of research data, but they also recognize the limits imposed by confidentiality protection. Recognizing that "access to or use of data may be restricted to safeguard the privacy of individuals", OECD Principles and Guidelines require researchers to take into account national laws on the protections of privacy [12]. The necessity to find an arrangement between data sharing and confidentiality protection is also a concern expressed in the draft of the Framework for Responsible Sharing of Genomic and Health-Related Data [14••].

Protecting confidentiality remains a primordial and continuous concern in sample and data sharing. No method is $100 \%$ effective in ensuring confidentiality, even anonymization. Scientists have shown that anonymized DNA samples could still be linked to the donor using publicly 
accessible information [15••]. Via the male surnames of participants from genealogy websites and the short tandem repeats on the $\mathrm{Y}$ chromosome as listed in a biobank, matches could be made. This demonstration underlines the importance of professionalism and the importance of trust in the researchers for the protection of confidentiality. No management modalities or technologies can ensure absolute privacy however. Awareness of the team members that handle samples and data should be prioritized, including educational measures and confidentiality certificates.

Thus, the PERSPECTIVE sharing agreement includes clauses on confidentiality protection. Researchers commit to "not use the Information in any manner that might expose [donor] identity or infringe their right to privacy, nor attempt to identify or contact any of the Donors" and "[to] hold and to procure the holding in strictest confidence". Local restrictions on confidentiality protection of samples and data usage could be added to the transfer agreements. These local restrictions become linked with the samples and data, and thus follow them through future projects. As previously explained, such distinct protection measures are allowed: both coded data and anonymized data are used-the latter decreasing research potential but raising privacy levels.

\section{(B) Incentives to Share Results}

Providing rapid and unrestricted access to data resulting from a project poses challenges with regard to the involvement of researchers. Those who contribute their knowledge and expertise to build the original concept and to find funding may justly expect recognition for their contribution [16, 17••]. Data and the knowledge derived therefrom are rarely mechanically produced. They originate from research guided by strong research leadership. It is not a trivial issue. Innovation depends largely-in addition to funding — on the researchers' willingness to test their hypotheses and to obtain results therefrom. Moreover, research funding is directly linked to publishing research findings; researchers do not want to compromise their ability to obtain further grants [18]. Why would researchers want "to be part of a system where they feel someone else can take advantage of their unsung contributions" [19]?

The Fort Lauderdale Statement which advocates rapid pre-publication data release recognizes that this sort of release "might conflict with a fundamental scientific incentive-publishing the first analysis of one's own data" [20]. Researchers who produce data fear of being "scooped" by those who interpret the ready-to-use valuable dataset [17••]. The tension between "benefit" sharing and the lack of incentives due to publishing and patenting prerogatives should never be seen as all or nothing: this is where both funders and universities can be of help. The incentives put in place to address this issue should "replicate the climate of trust and reciprocity that accompanies traditional and more informal data sharing" [18].

The data sharing plan of the PERSPECTIVE project was built on the initial framework of an existing consortium: the Breast Cancer Association Consortium (BCAC). This Consortium had previously adopted guidelines for data access and authorship. It was decided that these guidelines would be fully integrated into PERSPECTIVE albeit with some adjustments to respect local ethics requirements.

The BCAC Guidelines maintain a very delicate balance between the release of data and researcher attribution. First of all, data should be accessible to both Consortium members and non-members. Among the relevant rules included in these guidelines, a few illustrate how researcher incentives can be pursued at the same time as sharing:

- Approval by an access committee of any proposal to use the stored data (this process also allows the researcher who provided the data to opt out of the proposed analysis);

- Priority for members who proposed a particular SNP for leading the analysis and to have authorship;

- A 1-year period of exclusivity after the completion of the genotyping before publishing; and

- Specific rules to recognize and to promote authorship of researchers who provided the data.

Moreover, some adjustments or additions could be made to these guidelines in light of the sample and data sharing tools previously discussed. Indeed, restrictions on sharing could be added in the agreement depending on when the samples or data "enter" the loop of the project. Such restrictions must respect any restrictions originating from the samples and data provided. For instance, it could be an obligation concerning authorship or an additional delay before allowing unrestricted access [13].

\section{Conclusion}

It is true to say "big project, big issues" or "big data, big ethics" [21]. But it is also true that researchers can equip themselves to minimize these concerns. Researchers who initiate large-scale international projects are pioneers. Not only do they have to struggle to prove their scientific hypotheses, but they also need to overcome the barriers of ethical and legal requirements. They have our total respect for meeting both of these challenges. Multiple innovative strategies created to maximize the current process on a local level are probably the best solution for now, while global-hopefully international-solutions are being developed. 
Indeed, PERSPECTIVE is working on developing the concept of an ethics "Safe Harbour" that could allow for the mutual recognition of data access and ethics review between countries. This system would facilitate the harmonization of ethics reviews of international research projects while respecting transposable research ethics norms and principles. As a first step, it would require the endorsement of the Framework for Responsible Sharing of Genomic and Health-Related Data of the Regulatory and Ethics Working Group of the Global Alliance for Genomics and Health [13]. We hope this initiative will facilitate international project management and allow researchers to direct their full focus and energies on their scientific endeavors.

Acknowledgments The PERSPECTIVE project work is supported by the Québec Breast Cancer Foundation, by the Government of Canada through Genome Canada and the Canadian Institutes of Health Research, and by the Ministère de l'enseignement supérieur, de la recherche, de la science et de la technologie du Québec through Genome Québec. The authors would like to acknowledge Ms Shuang Shuang for her research assistance and revision of the text.

Disclosure E Lévesque and BM Knoppers both declare no conflicts of interest.

Human and Animal Rights and Informed Consent This article does not contain any studies with human or animal subjects performed by any of the authors.

\section{References}

Papers of particular interest, published recently, have been highlighted as

- Of importance;

-• Of major importance

1. Personalized Risk Stratification for Prevention and Early Detection of BC. This project is led by Pr Jacques Simard (Laval University) and Pr Bartha Maria Knoppers (McGill University). http://www.genomecanada.ca/medias/pdf/en/Simard.pdf. Accessed 26 June 2014.

2. Hébert P, Saginur R. Research ethics review: do it once and do it well. CMAJ. 2009;180:597.

3. Gold JL, Dewa CS. Institutional review boards and multisite studies in health services research: is there a better way? HSR. 2005;40:291-307.

4. Silverman H, Hull SC, Sugarman J. Variability among institutional review boards' decisions within the context of a multicenter trial. Crit Care Med. 2001;29:235-41.

5. Maxwell DJ, Kaye KI. Multicentre research: negotiating the ethics approval obstacle course. Med J Aust. 2004;181:460-1.

6. Ezzat H, Ross S, Dadelszen PV, et al. Ethics review as a component of institutional approval for a multicentre continuous quality improvement project: the investigator's perspective. HSR. 2010;10:223-8.
7. Onega T, Beaber EF, Sprague BL, et al. Breast cancer screening in an era of personalized regimens: a conceptual model and National Cancer Institute initiative for risk-based and preferencebased approaches at a population level. Cancer. 2014;. doi:10. 1002/cncr.28771.

8. Pace LE, Keating NL. A systematic assessment of benefits and risks to guide breast cancer screening decisions. JAMA. 2014;311:1327-35.

9. Chiarelli AM, Prumme MV, Muradali D, Majpruz V, Horgan M, Carrol JC, Eisen A, Meschino WS, Shumak RS, Warner E, Rabeneck L. Effectiveness of screening with annual magnetic resonance imaging and mammography: results of the initial screen from the Ontario high risk breast screening program. J Clin Oncol. 2014;. doi:10.1200/JCO.2013.52.8331.

10. Canadian Institutes of Health Research, Natural Sciences and Engineering Research Council of Canada, Social Sciences and Humanities Research Council of Canada. Tri-council policy statement: ethical conduct for research involving humans. 2nd ed. http://www.pre.ethics.gc.ca/eng/policy-politique/initiatives/tcps2eptc2/Default/ (2010). Accessed 2 June 2014.

11. Racine E, Bell E, Deslauriers C. Canadian research ethics board and multisite research: experiences from two minimal-risk studies. IRB: Ethics Human Res. 2010;32:12-8.

12. Genome Canada. Data release and resource sharing policy. http:// www.genomecanada.ca/medias/PDF/EN/DataReleaseandResource SharingPolicy.pdf (2010). Accessed 2 June 2014.

13. Organisation for Economic Co-operation and Development. OECD principles and guidelines for access to research data from public funding. http://www.oecd.org/science/sci-tech/38500813. pdf (2007). Accessed 2 June 2014.

14. •• Regulatory and Ethics Working Group of the Global Alliance for Genomics and Health. Framework for responsible sharing of genomic and health-related data, draft \#7. (2014). http://genomic sandhealth.org/our-work/work-products/framework-responsiblesharing-genomic-and-health-related-data. This Framework aims to establish a set of foundational principles for responsible research conduct and oversight of research data systems.

15. - Gymrek M, McGuire AL, Golan D et al. Identifying personal genomes by surname inference. Science. 2010;339:321-324. This study demonstrates that publicly available data can be used to infer personal information and re-identify individuals.

16. Pearce N, Smith AH. Data sharing: not as simple as it seems. Environ Health. 2011;10:107-13.

17. •- Expert Advisory Group on Data Access (UK). Establishing incentives and changing cultures to support data access. http:// www.wellcome.ac.uk/stellent/groups/corporatesite/@msh_peda/ documents/web_document/wtp056495.pdf (2014). Accessed 23 June 2014. This report seeks to understand the factors that help researchers in making data more widely available. It makes a series of recommendations to develop mechanisms that encourage and reward data sharing.

18. Gitter DM. The challenges of achieving open-source sharing of biobank data. Biotechnol Law Rep. 2010;29:623-35.

19. Kaye J, Heeney C, Hawkins N, et al. Data sharing in genomics: re-shaping scientific practice. Nat Rev Genet. 2009;10:331-5.

20. The Wellcome Trust. Sharing data from large-scale biological research projects: A system of tripartite responsibility. Report of a meeting organized by the Wellcome Trust at Fort Lauderdale, USA (the "Fort Lauderdale Statement"). http://www.wellcome. ac.uk/stellent/groups/corporatesite/@policy_communications/doc uments/web_document/wtd003207.pdf (2003). Accessed 26 June 2014.

21. Dove ES, Knoppers BM, Zawati MH. Towards an ethics safe harbor for global biomedical research. J Law Biosci. 2014;1:3-51. 